LBL --32203

DE93 007649

\title{
Metal Ion Implantation for Large Scale Surface Modification
}

\author{
Ian G. Brown \\ Accelerator and Fusion Research Division \\ Lawrence Berkeley Laboratory \\ University of California \\ Berkeley, California 94720
}

October 1992

Invited Paper presented at the 39th Symposium of the American Vacuum Society, Chicago, Ilinois, November 9-13, 1992

This work was supported by the U.S. Army Research Office and the Office of Naval Research under Contract No. ARO 116 R9, and by the Electric Power Research Institute under Award No. RP2426-27, through the U.S. Department of ènergy under Contract No. DE-AC03-76SF00098.

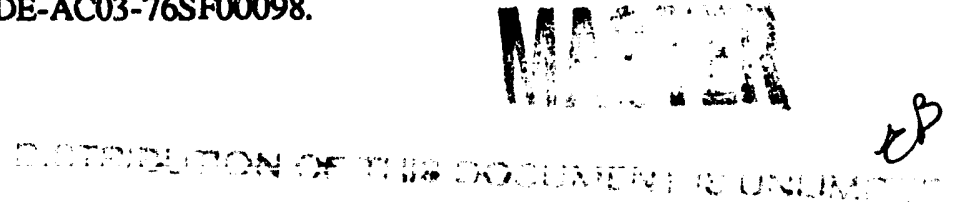




\section{Abstract}

Intense energetic beams of metal ions can be produced by using a metal vapor vacuum arc as the plasma discharge from which the ion beam is formed. We have developed a number of ion sources of this kind and have built a metal ion implantation facility which can produce repetitively pulsed ion beams with mean ion energy up to several hundred $\mathrm{keV}$, pulsed beam current of more than an ampere, and time averaged current of several tens of milliamperes delivered onto a downstream target. We've also done some preliminary work on scaling up this technology to very large size. For example, a $50-\mathrm{cm}$ diameter $\left(2000 \mathrm{~cm}^{2}\right)$ set of beam formation electrodes was used to produce a pulsed titanium beam with ion current over 7 amperes at a mean ion energy of 100 $\mathrm{keV}$. Separately, a dc embodiment has been used to produce a dc titanium ion beam with current over $600 \mathrm{~mA}$, power supply limited in this work, and up to 6 amperes of de plasma ion current was maintained for over an hour. In a related program we've developed a plasma immersion method for applying thin metallic and compound films in which the added species is atomically mixed to the substrate. By adding a gas flow to the process, well-bonded compound films can also be formed; metallic films and multilayers as well as oxides and nitrides with mixed transition zones some hundreds of angstroms thick have been synthesized. Here we outline these parallel metal-plasma-based research programs and describe the hardware that we've developed and some of the surface modification research that we've done with it.

\section{INTRODUCTION}

The vacuum arc is a plasma discharge that takes place between metallic electrodes in vacuum, in the process producing a copious flux of dense metal plasma. The plasma is generated at a small number of tiny points on the surface of the cathode, called cathode spots and of dimension a few microns, at which the arc current is concentrated to an extremely high current density, of order $10^{8}$ $-10^{12}$ amperes $\mathrm{cm}^{-2}$. The metal plasma energetically plumes away from the cathode in a manner reminiscent of a laser-produced plasma plume. The cathode remains cool in bulk (ie, except locally at the cathode spots during plasma formation), and a background gas is not required - the plasma generation process is neither an evaporative nor a sputtering process. It is a very efficient process, as plasma preparation schemes go. This means of metal plasma production can be harnessed adyantageously to forge some interesting plasma and ion beam surface modification tools.

One way in which the vacuum arc plasma can be used is within an ion source. Intense, energetic beams of metal ions can be produced, which in tum can be used to carry out high current metal ion implantation for material surface modification. The laboratory-scale, vacuum-arc-based, metal ion implanter that we've developed operates in a repetitively pulsed mode and can produce metal ion beams with mean ion energy up to several hundred $\mathrm{keV}$, pulsed beam current of more than an ampere, and time-averaged current of several tens of milliamperes delivered onto a downstream target. Virtually all of the solid metals of the periodic table can be used. We have explored the application of this implantation technique to several different areas of materials modification.

Recently we've further developed the vacuum arc ion source technology and carried out some preliminary tests of a dc source embodiment and very large area beam formation electrodes. A $600 \mathrm{~mA}$ dc titanium ion beam was formed at $18 \mathrm{keV}$ using an $18-\mathrm{cm}$ diameter extractor. Plasma measurements indicated that a dc plasma ion current of up to 6 amperes was available for beam formation (extractable at high voltage than we had available). Separately, we've formed beam from a $50-\mathrm{cm}$ diameter $\left(2000 \mathrm{~cm}^{2}\right)$ set of extractor grids using a pulsed plasma gun, producing a $100 \mathrm{keV}$ titanium ion beam with a current of 7 amperes. Thus the research base of our metal ion source program has arrived at the stage where we've demonstrated the production of multi-ampere beams, dc operation, and beams of very large cross-sectional area. It is possible to combine these features into an integrated, industrially-relevant, metal ion implanter of very substantial scale. The facility we envision would produce a dc ion beam of current variable from $100 \mathrm{~mA}$ up to several 
amperes, with mean ion energy in the broad range $30-300 \mathrm{keV}$, of species any of several dozen different elements as well as multi-ion species, and of cross-sectional area one to several square meters. An ion implantation facility of this scale would advance the state of the art, measured by the crucial parameter of beam current, by around two orders of magnitude, and would be able to implant very large area workpieces to high dose. Most importantly, the unit cost of metallurgical surface modification by ion implantation would be vastly reduced.

Another way in which the vacuum-arc-produced metal plasma can be harnessed is for the formation of metallic thin films and multilayers. By repetitively pulse biasing the substrate while it is immersed in the metal plasma, one can form thin films of metals, compour:ds and composites on material surfaces with atomic mixing of the film to the underlying substrate. The added species can be implanted below the surface or built up as a film with an atomically mixed interface with the substrate, and more than one kind of metal species can be applied, either simultaneously or sequentially. Surface structures can be fabricated including coatings and thin films of single metals, tailored alloys or metallic multilayers, and they can be implanted or added onto the surface and ion beam mixed. By adding a gas flow to the plasma implantation and deposition processes, well-bonded ceramic films can also be formed. The process parameters can be varied to fabricate a wide range of surface structures at the atomic level. We've demonstrated the method by synthesizing a number of metallic films as well as oxide and nitride films with mixed transition zones up to about $1000 \AA$ thick.

Here we review our recent work in materials synthesis and surface modification based on these applications of the metal vapor vacuum arc plasma.

\section{Metal Plasma PROdUCtion With VACUUM ARCS}

The metal vapor vacuum arc [1] is a kind of plasma discharge that takes place between metallic electrodes in a high vacuum environment and it is a prolific producer of dense metal plasma. These kinds of plasma sources have been used widely for Physical Vapor Deposition (PVD) of various metal coatings [2,3] and for the formation of TiN protective coatings [4,5], and industrial arc source deposition equipment is readily available on the market. The vacuum arc is commonly also called a 'cathodic arc'. Cathodic arc PVD facilities are large pieres of equipment and are designed to apply metallic coatings to large substrate areas; the titanium nitriding of cutting tools and other components in a large batch processing mode is a typical application. Most of our applications have been at the other extreme - small sources with fine control over the plasma flux, and operated in a repetitively pulsed mode.

The fundamental phenomenon that drives the vacuum arc is that of cathode spot formation minute regions of intense current concentration which reside on the surface of the cathode and at which the solid cathode material is vaporized, ionized, and injected into the interelectrode arc region. A typical vacuum arc discharge might consist of from one to many dozens of such spots. A very complete review of the entire field of metal vapor arc discharges has been given by Lafferty [1] and a review of cathode spot behavior has been given by Lyubimov and Rakhovskii [6].

For the work described here the arc discharge was driven by a simple L-C pulse line of impedance $1 \Omega$ and pulse length $250 \mu$ s charged to a voltage of up to several hundred volts with a dc power supply. A high voltage pulse applied to a trigger electrode initiates a surface spark discharge between a coaxial trigger electrode and the central cathode, which in turn causes the main anode-cathode circuit to close due to the spark plasma, and the vacuum arc proceeds. Typically the source is operated at a repetition rate of up to several tens of pulses per second, limited by power supply and thermal considerations. The properties of the metal plasma, as reflected in the extracted ion beam, have been extensively studied as part of our Mevva ion source R\&D program [7-10]; (we use the acronym Mevva for metal vapor vacuum arc). The source works well with virtually all the solid metals of the periodic table; we have operated with 50 different metallic 
elements [11,12] - Li, C, Mg, Al, Si, Ca, Sc, Ti, V, Cr, Mn, Fe, Co, Ni, Cu, Zn, Ge,Sr, Y, Zr, $\mathrm{Nb}, \mathrm{Mo}, \mathrm{Pd}, \mathrm{Ag}, \mathrm{Cd}$, In, Sn, Sb, Ba, La, Ce, Pr, Nd, Sm, Gd, Dy, Ho, Er, Tm, Yb, Hf, Ta, W, Ir, $\mathrm{Pt}, \mathrm{Au}, \mathrm{Pb}, \mathrm{Bi}, \mathrm{Th}, \mathrm{U}$ - and a range of alloys and compounds [13].

\section{MEVVA ION IMPLANTATION}

\section{A. Repetitively pulsed Mevva implanter}

The Mevva ion source program was begun initially for the production of high current uranium ion beams for fundamental heavy ion nuclear physics research. For this application the source was used in a pulsed mode of operation and at low duty cycle so as to match the injection requirements of the LBL heavy ion synchrotron, the Bevatron. As it became clear that the source could offer some advantages not only for accelerator injection but also for ion implantation, the need for changing the parameters in several different ways became apparent. For example whereas for accelerator injection a small area, low emittance beam is required to be delivered at a pulse length and duty cycle to match that of the accelerator, for ion implantation for (non-semiconductor) materials surface modification it is usual that a large area beam of high duty cycle is required and beam emittance is not very important. The Mevva V source [14] was the first to be made specifically for ion implantation application; it is shown in Figure 1. It has a $10 \mathrm{~cm}$ diameter extractor and is well cooled so as to allow operation at the highest duty cycle that our electrical system can support. It incorporates a multi-cathode design and one can switch rapidly between any of 18 separate cathode species.

Repetitively pulsed operation of the Mevva ion source typically entails parameters in the following range: arc current 100 A pulsed, arc voltage (burning voltage, during the arc-on time) $20 \mathrm{~V}$, beam current $0.1-2$ A pulsed, beam voltage $20-100 \mathrm{kV}$, beam energy $20-300 \mathrm{keV}$ (the ion mean charge state can be from 1 to 3 depending on the metal ion species chosen $[11,12])$. Duty cycle might typically be up to about $1 \%$ or so, and the time-averaged arc power dissipation within the source $20 \mathrm{~W}$, the time-averaged beam power $500 \mathrm{~W}$, and the time-averaged beam current a few tens of milliamperes.

The ion source development test stand has slowly evolved into an ion implantation facility using the Mevva V source to produce the metal ion beams; a schematic is shown in Figure 2. The facility has been used for exploratory research for a variety of different ion implantation applications related to the surface modification of metals, ceramics, glass, polymers, high- $T_{c}$ superconductors, and semiconductors [15-17]. Research projects that we've carried out include, for example: a fundamental study of the range of metal ions in carbon [18], high temperature oxidation inhibition of $\mathrm{Cr}_{2} \mathrm{O}_{3}$-forming alloys by $\mathrm{Y}$ ion implantation [19]; improving the pitting corrosion resistance of $\mathrm{Al}$ by $\mathrm{Ti}$ ion implantation [20]; modification of the optical transmission characteristics of glass [21]; synthesis of buried single crystal $\mathrm{Si}_{1-\mathrm{x}} \mathrm{Ge}_{\mathrm{x}}$ alloy layers in $\mathrm{Si}$ [22]; ; photoluminescence of GaAs and InP by $U$ and Th implantation doping [23]; synthesis of buried conducting $\mathrm{IrSi}_{3}$ layers in $\mathrm{Si}$ [24]; $\mathrm{Cu}$ and $\mathrm{W}$ implantation into Si for seeding for plating [25]; very high dose implantation of $\mathrm{Ti}$ into $\mathrm{Si}$ for study of the "anomalously high penetration effect"; $\mathrm{Cu}$ and $\mathrm{Y}$ into $\mathrm{YBa}_{2} \mathrm{Cu}_{3} \mathrm{O}_{7}$ high temperature superconducting thin films for tailoring the sioichiometry [26]; Pt into steel for hydrogen embrittlement studies [27]; Hf into steel for hardness improvement [28]; and many more.

\section{B . Anatomy of a dc vacuum arc ion implantation facility}

It is possible to form dc beams of metal ions with beam current two or three orders of magnitude greater than the mean currents obtained with the repetitively pulsed Mevva source versions. For dc operation the source parameters are increased by the inverse duty cycle, ie, by a factor of approximately 100 . Then the arc power dissipation can be around $2 \mathrm{~kW}$ and the beam power $50 \mathrm{~kW}$. It is not possible to reduce the arc current to arbitrarily low levels; for example one 
might wish to reduce the arc current to $1 \%$ of its previous (pulse operation) value so as to maintain the same mean power values. But the arc will not operate at a current level of 1 ampere - it extinguishes well before this value is obtained. It is a well-established property of vacuum arcs that there is a minimum current level at which they will stay alive and below which the cathode spots are not maintained [1]. For an acceptably low probability of plasma extinction over long periods of dc operation, this minimum arc current can be taken as approximately $100 \mathrm{~A}$; for some cathode materials a higher current will be required and for others a lower current may be possible. Thus power dissipation and cooling are primary concerns that determine the choice of parameters such as cathode configuration and extractor size. Heat is generated at the front face of the cathode, so a flat cylindrical geometry is used with efficient water cooling at the rear surface. The rate of removal of cathode mass by arc erosion has been studied by a number of authors [29-31], and for most metals with not too low melting points the erosion rate is in the range 20 to 60 micrograms per Coulomb of arc current. The necessary cathode mass can then be estimated to be of order $1 \mathrm{kG}$ per day of steady operation. The dc beam power is high. We want to design for a large beam area both so as not to melt the implantation target (if implantation is the application), and also for nottoo-high beam power density dissipation in the beam formation electrodes themselves. Thus part of our design approach for a dc source is to use a very large area beam, and to obtain this large cross-sectional area by expanding the metal plasma prior to extraction by using very large area beam formation electrodes (extractor grids).

\section{Basic experiments with very large source}

We have made an elemental dc Mevva ion source and carried out some preliminary tests with it. Separately but as part of the same program objectives, we have also made and tested a set of very large area beam formation electrodes. These are the two critical ingredients needed for a very large dc implantation facility.

The dc plasma generator performed well, and we were able to operate it continuously for periods of up to several hours. To measure the ion current available for extraction from the plasma source, a biased collector plate was positioned so as to intercept most of the plasma stream; a photograph of the gun within a magnetic guide field structure used to duct the plasma to a terminating current collector plate is shown in Figure 3. A dc titanium plasma ion current of up to 6 amperes was measured. To demonstrate actual production of extracted dc titanium ion beam, the collector plate was replaced by an $18 \mathrm{~cm}$ diameter set of multi-aperture beam formation grids and the extracted beam current measured. In these experiments we were extremely limited by available electronics and by heating of components. We measured a current of $600 \mathrm{ma}$ at an extraction voltage of just $9 \mathrm{kV}$, corresponding to about $20 \mathrm{keV}$ titanium mean ion energy. Then we made a very large area extractor that was fed with the plasma from a pulsed titanium plasma gun. These experiments have been described in more detail in [32]. A photograph of the disassembled $50 \mathrm{~cm}$ extractor is shown in Figure 4, together with a smaller Mevva ion source embodiment and two subminiature versions. This configuration appears to be very efficient in terms of plasma utilization, and we have formed titanium beams with diameter $33 \mathrm{~cm}$ (FWHM) and ion current up to 7 amperes at $100 \mathrm{keV}$ mean ion energy (and up to 20 amperes peak at the current overshoot part of the beam pulse). It is interesting to note that the ratio of beam current to arc current reached nearly $5 \%$, and since the total metal plasma ion current generated by the vacuum arc is about $10 \%$ of the arc current fairly universally $[1,33]$, and the grid transparency is $40 \%$, the plasma expansion chamber and large area extractor configuration used here are very efficient in terms of plasma utilization. These results confirm the viability of dc and very large area extractor Mevva ion source embodiments, and demonstrate that metal ion beams with beam current of order an ampere to tens of amperes and with beam diameter of order a meter or more can be efficiently produced.

\section{Description of a conceptual very large implanter}

We propose a facility that would incorporate a large dc metal ion source of the kind described above. The precise parameters, characteristics, size, cost and other features of the implanter could be designed over a wide range, to suit a wide range of applications. For example, the beam current 
could be as "low" as about 100 ma or so, just a factor of several greater than the largest of the conventionally available ion implanters on the market today, or it could be of order 10 amperes or more, about two orders of magnitude greater than the present state-of-the-art. By stacking units it would be possible to produce beam clusters having total ion current up to around 100 amperes or more, but the concern of what to do with such a beam battery is daunting if it is also of high ion energy. The beam need not be axisymmetric but could be of rectangular or slit cross-section as required. The powers involved would be large by laboratory standards but not at all by industrial standards: a high current version of the implanter might use a $100 \mathrm{keV}, 10$ ampere beam, corresponding to a beam power of about $1 \mathrm{MW}$ (depending on the ion mean charge state) and a total device power of perhaps several MW including pumping and cooling. Target cooling would be important, and it is probable that the maximum tolerable target temperature would determine the design of the facility, via the beam current and beam size at the target. The beam current density profile could be tailored, if uniformity is important for a particular application, via the plasma density profile prior to extraction, or via the detailed extractor design, or via the clustering of individual and separately controlled ion sources, or simply by beam-limiting apertures given that a surfeit of beam is likely. The ion source being vacuum-arc-driven and presenting no gas load to the system, the vacuum pumping requirements will probably not be overwhelming; the system pressure should be somewhere near the $10^{-5}$ Torr region. Given this rather modest base pressure requirement, a quick turn-around load-lock system could be used for the rapid implantation of large area components or materials in a batch processing mode, or a differentially pumped system might be feasible for the implantation of continuously fed sheet material. The general features of the facility are outlined in Table $\mathrm{I}$.

\section{METAL PLASMA IMMERSION SURFACE PROCESSING}

\section{A. Background and concept}

Ion implantation is used to energetically inject ions to depths of hundreds or thousands of Angstroms below the material surface, while a surface film can be deposited onto the substrate by a low energy flux of plasma or neutrals. Many variants and hybrids of these extremes have been investigated, such as ion beam mixing [34] and ion beam assisted deposition (IBAD) [35]. For example a condensible (eg, metal) species deposited at low energy can be driven into the substrate by knock-on collisions with energetic ions. Much progress has been made in a number of means of implementation of this recoil implantation technique. A unique means of carrying out ion implantation has been developed, principally by Conrad and co-workers [36,37] and also by others [38-41], in which the object to be implanted is immersed in a plasma and repetitively pulse-biased to high negative voltage, thereby accelerating ions across the plasma sheath into the substrate. This technique has been called plasma source (or plasma immersion) ion implantation (psii or piii). PIII has been shown to be an effective tool for both metallurgical [36-38] and semiconductor [39-41] ion implantation.

When the plasma in which the object is immersed is a metal plasma, the plasma condenses and remains on the substrate as a film, and qualitatively new and different consequences follow. Other features can be added to the basic plasma immersion pulse biasing technique such as: multiple metal plasma guns, perhaps of different metal species; variation of pulse length of the metal plasma pulse; phasing of the ion acceleration pulse (piii phase) with respect to the plasma pulse (low energy plasma deposition phase); and finally all of these parameters can be tailored throughout the duration of the surface processing operation to fabricate a wide range of surface structures at the atomic level. By adding a gas flow to the deposition and implantation processes, the variety of films that can be formed is greatly expanded, and not only metallic films but also films of compounds including ceramic oxides, for example, can be formed.

The process can be used to form surface metal film structures that are of importance to a number of different areas, such as for the fabrication of metallic multilayers with novel mechanical 
properties that have super-strong adhesion to the substrate metal. Ceramic films can be formed on metal surfaces with an atomically mixed transition zone and very good adhesion properties; these applications of the process could be important for the formation of well bonded hard coatings and for the development of ceramic engines. The bonding transition zone between substrate and film can in principle be tailored to provide a good match between substrate and film properties, for example thermal expansion or lattice constant.

We have demonstrated this processing technique in a number of different experiments. As a confirmation of the concept, yttrium was deposited onto and recoil mixed into silicon with an atomically mixed transition zone extending into the substrate for about $500 \AA$. A quarter-micron film of Pt was formed on and mixed into Al. We formed a 6-layer multilayer structure of $\mathrm{Y}$ and $\mathrm{Ti}$ in which the first and last layers were ion stitched to the material below. And we've formed oxide and nitride films with mixed transition zones of order $1000 \AA$ thick thereby producing ceramic thin films atomically mixed to the underlying steel substrate.

\section{B. Experimental set-up}

These demonstration experiments were carried out in a vacuum vessel pumped cryogenically to a pressure of about $1 \times 10^{-6}$ Torr, using our pulsed vacuum arc plasma guns [42] with various cathode materials. Previous work [11-12] has shown that the vacuum arc metal plasma is multiply ionized with a mean charge state between 1 and 3 depending on the metal species used; thus, when implanted, the mean ion energy is greater than the applied pulse voltage by this factor. Prior to implantation (repetitive application of the high voltage pulse), the plasma ion current collected by the substrate during each pulse was measured by biasing the substrate to about $-200 \mathrm{~V}$ and measuring the ion saturation current in the usual way [43]. For synthesizing compound and ceramic films, a gas jet was used to inject a suitable gas (oxygen or nitrogen) into the vicinity of the metal plasma and the depositing film. The gas then participates in the implantation and/or deposition phases of the processing.

The processing consisted of two component parts: In the first phase the plasma guns were operated in a short-pulse mode (a few microseconds) and the substrate repetitively biased to high negative voltage so as to implant the ionized material (metal, and gas if any) well below the surface; this is the piii phase of the process. In the second phase the plasma guns were operated in a longpulse mode (250 microseconds) and the substrate was kept at or near ground potential; this is the film deposition phase of the process. The combination of these two parts results in a film which is atomically mixed to the substrate.

\section{Experimental results}

\section{Confirmation of the basic idea: $Y$ on Si}

The plasma gun was operated with yttrium and the silicon substrate was repetitively pulse biased with $-30 \mathrm{kV}, 1 \mu \mathrm{s}$ pulses timed for the maximum of the plasma pulse. The equivalent timeaveraged ion implantation current was several tens of microamperes onto the substrate of area several square centimeters. The mean charge state of ions produced by the vacuum arc plasma is know to be 2.3 for yttrium $[11,12]$, and thus the $30 \mathrm{kV}$ voltage pulse yields a mean ion energy of $70 \mathrm{keV}$. Another sample was prepared under identical conditions except that the high voltage implantation pulse was not applied, thus providing a non-implanted sample for comparison. The samples were analyzed by $2.0 \mathrm{MeV} \mathrm{He}{ }^{+}$Rutherford Backscattering Spectrometry (RBS). The results are shown in Figure 5. The RBS resolution is indicated by the Gaussian-shaped profile obtained from the film that is deposited on the surface of the silicon when the pulse biasing is not applied. With the pulse biasing, the depth profile extends below the surface and has a shape that is qualitatively as expected for a combination of conventional ion implantation, recoil implantation, and surface deposition. A nominal depth of the implanted region (half width of the profile, with an ad-hoc correction for the RBS resolution) is approximately $500 \AA$, which compares well with the TRIM-calculated [44] range for $70 \mathrm{keV} \mathrm{Y}$ into Si of $470 \AA$. The RBS-measured dose is $1.0 \times 10^{16}$ 
atoms $/ \mathrm{cm}^{2}$, in agreement with the dose expected from the accumulated number of pulses. This simple application of the method thus confirms that the technique works fundamentally as expected.

\section{Bonded thin metal films: Pton Al}

The plasma gun was fitted with a Pt cathode and the substrate was Al. The pulse biasing (piii) phase was followed by a long-pulse deposition phase so as to build up a film of thickness about $0.25 \mu \mathrm{m}$. Thus in this case we produced a simple platinum film that is ion stitched into the aluminum substrate. The RBS data are shown in Figure 6.

\section{Bonded metallic multilavers: TilY on Si}

Two plasma guns were used, one containing an yttrium cathode and the other titanium. The sequence of operations was: yttrium was implanted into the substrate at an energy of $70 \mathrm{keV}$ and a dose of $1 \times 10^{16}$ atoms $/ \mathrm{cm}^{2}$, followed by a low energy (about $50 \mathrm{eV}$; no high voltage pulse applied) deposition of yttrium to build up a layer of thickness several hundred Angstroms (the pulse length of the yttrium plasma pulse was increased from $2 \mu s$ up to $250 \mu$ s for this phase); then successive layers of Ti-Y-Ti-Y-Ti were added, each of several hundred Angstroms thickness; the final Ti layer was started out by implanting Ti into the underlying Y layer at an energy of about 50 $\mathrm{keV}$ and a dose of about $1 \times 10^{15}$ atoms $/ \mathrm{cm}^{2}$, then followed by the low energy, longer pulse length part of the final Ti phase. The RBS data are shown in Figure 7. The multilayer structure is evident; the layers have a thickness of approximately $400 \AA$, corresponding to a deposited particle density of approximately $1.4 \times 10^{17}$ atoms $/ \mathrm{cm}^{2}$ for $\mathrm{Y}$ and $2.5 \times 10^{17}$ atoms $/ \mathrm{cm}^{2}$ for Ti.

\section{Bonded ceramic films: $\mathrm{Al}_{2} \mathrm{O}_{3}$ on steel}

The plasma gun was operated with an aluminum cathode and the substrate was polished stainless steel. An appropriately designed gas jet arrangement was used to inject oxygen into the plasma/substrate interaction region. The metal plasma immersion processing technique was applied so as to form an atomically mixed interface region followed by a film of thickness about $0.2 \mu \mathrm{m}$. With some judicious selection of the various operational parameters, we were able to synthesize a stoichiometric film of alumina with mixing into the stainless steel substrate of both the aluminum and oxygen down to a substrate depth of order $1000 \AA$. "3-dimensional" Auger data of depth profiles are shown in Figure 8, where one can see the $\mathrm{Al}$ and $\mathrm{O}$ profiles of the alumina tail into the substrate, as viewed both from the substrate side looking toward the interface, and from the surface side looking into the bulk. Note that the close-to-stoichiometric Al:O ratio is maintained throughout most of the film (although not in the intermixed zone). Further confirmation of the presence of an atomically mixed transition zone as indicated by the Auger data was provided by an independent analysis of the same sample by Rutherford backscattering spectrometry. The point of these data is the presence of the slow mixing of the $\mathrm{Al}$ and $\mathrm{O}$ into the substrate material.

\section{CONCLUSIONS}

The metal vapor vacuum arc ion source provides a unique tool for carrying out metal ion implantation. The versatility of the technique for laboratory ion implantation has been well established in a variety of materials modification experiments. The implanter operates in a broadbeam, non-mass-analyzed mode, and the beam current is repetitively pulsed with a maximum beam current of about 1 amp or more and a time-averaged beam current of ten to several tens of $\mathrm{mA}$; ion energy can be varied up to several hundred $\mathrm{keV}$. The ion source technology needed to develop a very large metal ion implanter has been demonstrated in the laboratory. Critical parameters of such a very large scale facility, such as beam current and size, could be greater than the present state of the art by more than two orders of magnitude, and the cost of implantation could be less than with present technology by two orders of magnitude. Applications could include direct ion implantation as well as IBAD and other hybrid techniques for the modification of the surface properties of metals, ceramics, glass, polymers, etc., on an industrial scale, high throughput, low unit cost basis. 
The metal plasma immersion surface modification, or "mpi processing", technique that we've described is new and can be extended beyond the limitations of the experiments described here in many ways. The method can be scaled up to produce atomically-bonded macroscopically-thick coatings; the method is not limited to thin films. Similarly the scale-up could be to large substrate area and high throughput. One can envision a computer controlled processing system, perhaps with feedback from monitors of various kinds, whereby it could be possible to build up highly complex structures of metals, ceramics, and other composites and compounds, having films and multilayers with sharp or tailored interfaces between layers and to the substrate.

\section{ACKNOWLEDGEMENTS}

The work described here was carried out over a period of years as a group effort. The mechanical design and fabrication of the sources and other equipment was done by a team led by Bob MacGill and including Mike Dickinson and Bob Wright, and the electrical and electronics support was provided by Jim Galvin, Jan deVries, Bud Leonard, Mark Rickard, Tom McVeigh and Martin Ramella. The research programs - vacuum arc, ion source, plasma deposition, plasma immersion, and materials characterization - have benefited immensely from the contributions of my colleagues Drs. Simone and Andre Anders, Xavier Godechot, Igor Ivanov, Xiang Yao, and Kin-Man Yu. The materials research has been done with many collaborators at LBL and at other laboratories, to whom I am greatly indebted. This work was supported by the U.S. Army Research Office and the Office of Naval Research under Contract No. ARO 116-89, the Electric Power Research Institute under Award number RP2426-27, and the Department of Energy under Contract No. DE-AC03-76SF00098. 


\section{References}

1. See, for instance, J. M. Lafferty, ed., "Vacuum Arcs - Theory and Application", (Wiley, NY, 1980).

2. R. L. Boxman, S. Goldsmith, S. Shalev, H. Yaloz and N. Brosh, Thin Solid Films 139, 41 (1985).

3. D. M. Sanders, "Review of Ion Based Coating Processes Derived from the Cathodic Arc", J. Vac. Sci. Tech. A7, 2339 (1989).

4. C. Bergman, in "Ion Plating and Implantation", edited by R. F. Hochman, (American Society for Metals, USA, 1986). (Proceedings of the ASM Conference on Applications of Ion Plating and Implantation to Materials, June 3-5, 1985, Atlanta, GA).

5. P. A. Lindfors, loc. cit. [4].

6. G. A. Lyubimov and V. I. Rakhovskii, Sov. Phys. Usp. $21(8), 693$ (1978).

7. I. G. Brown, J. E. Galvin, and R. A. MacGill, Appl. Phys. Lett. 47, 358 (1985).

8. I. G. Brown, J. E. Galvin, B. F. Gavin, and R. A. MacGill, Rev. Sci. Instrum. 57, 1069 (1986).

9. I. G. Brown, in "The Physics and Technology of Ion Sources", I. G. Brown editor, (Wiley, N.Y., 1989).

10. I. G. Brown, Rev. Sci. Instrum. 63, 2351 (1992).

11. I. G. Brown, B. Feinberg, and J. E. Galvin, J. Appl. Phys. 63, 4889 (1988).

12. I. G. Brown and X. Sodechot, IEEE Trans. Plasma Sci. PS-19, 713 (1991).

13. J. Sasaki and I. G. Biown, J. Appl. Phys. 66, 5198 (1989).

14. I. G. Brown, J. E. Gnisin, R. A. MacGill and F. J. Paoloni, Rev. Sci. Instrum. 61, 577 (1990).

15. I. G. Brown, M. R. Dickinson, J. E. Galvin, X. Godechot and R. A. MacGill, Nucl. Instrum. Meth. Phys. Res. B55, 506 (1991).

16. I. G. Brown, M. R. Dickinson, J. E. Galvin, X. Godechot and R. A. MacGill, J. Materials Eng. 13, 217 (1991).

17. I. G. Brown, M. R. Dickinson, J. E. Galvin, X. Godechot and R. A. MacGill, Surface and Coatings Technol. 51, 529 (1992).

18. G. Dearnaley, J. L. Ing, S. Sugden, I. G. Brown and X. Godechot, Surface and Coatings Technol. 51, 364 (1992).

19. P. Hou, V. Chia and I. Brown, Surface and Coatings Technol. 51, 73 (1992).

20. X. Yao, K. M. Yu, I. G. Brown, T. R. Devine, Jr., C. Kumai, and I. C. Ivanov, "Effect of Titanium Ion Implantation on Pitting Corrosion Behavior of Aluminum", 8th Int. Conf. on Ion Beam Modification of Materials, Heidelberg, Germany, September 7-11, 1992.

21. X. Yao, I. G. Brown and M. D. Rubin, "Modification of the Optical Spectra of Glass by Metal Ion Implantation", 8th Int. Conf. on Ion Beam Modification of Materials, Heidelberg, Germany, September 7-11, 1992.

22. K. M. Yu, I. G. Brown and S. Im, Mat. Res. Soc. Symp. Proc. 235, 293 (1992).

23. G.S. Pomrenke, R.L. Hengehold, Y.K. Yeo, I.G. Brown and J.S. Solomon, J. Appl. Phys. 67, 2040 (1990).

24. K. M. Yu, B. Katz, I. C. Wu and I. G. Brown, Nucl. Instrum. Methods B58, 27 (1991).

25. X. Y. Qian, M. H. Kiang, N. W. Cheung, I. G. Brown, X. Godechot, J.E.Galvin, R. A. MacGill and K. M. Yu, Nucl. Instrum. Meth. Phys. Res. B55, 893 (1991).

26. M. Rubin, I.G. Brown, E. Y in and D. Wruck, J. Appl. Phys. 66, 3940 (1989).

27. P. Buckley, B. Placzankis, L. J. Lowder, I. G. Brown and R. Brown, "Noble Metal Implantation to Reduce Hydrogen Embrittlement in Steels", Int.Conf. on Metallurgical Coatings and Thin Films, San Diego, CA, April 22-26, 1991; Surface and Coatings Technol. (1991).

28. D. M. Rueck, D. Boos and I. G. Brown, "Improvement in Wear Characteristics of Steel Tools by Metal Ion Implantation", 8th Int. Conf. on Ion Beam Modification of Materials, Heidelberg, Germany, September 7-11, 1992; to be published in Nucl. Instrum. Meth. Phys. Res. 
29. C. W. Kimblin, J. Appl. Phys. 44, 3074 (1973).

30. C. W. Kimblin, J. Appl. Phys. 45,5235 (1976).

31. I. G. Brown, IEEE Trans. Plasma Sci. PS-18, 170 (1990).

32. I. G. Brown, M. R. Dickinson, J. E. Galvin and R. A. MacGill, Rev. Sci. Instrum. 63 , 2417 (1992).

33. I. G. Brown, IEEE Trans. Plasma Sci. PS-15, 345 (1987).

34. L. E. Rehn and P. R. Okamoto, Nucl. Instr. and Meth. B39, 104 (1989).

35. G. K. Wolf and W. Ensinger, Nucl. Instr. and Meth. B59/60, 173 (1991).

36. J. R. Conrad, J. L. Radtke, R. A. Dodd, F. J. Worzala and N. C. Tran, J. Appl. Phys. 62, 4591 (1987).

37. J. T. Scheuer, M. Shamim and J. R. Conrad, J. Appl. Phys. 67, 1241 (1990).

38. J. Tendys, I. J. Donnelly, M. J. Kenny and J. T. A. Pollock, Appl. Phys. Lett. 53, 2143 (1988).

39. H. Wong, X. Y. Qian, D. Carl, N. W. Cheung, M. A. Lieberman, I. G. Brown and K. M. Yu, Mat. Res. Soc. Symp. Proc. 147, 91, (MRS, Pittsburgh, 1989).

40. X. Y. Qian, H. Wong, D. Carl, N. W. Cheung, M. A. Lieberman, I. G. Brown and K. M. Yu, 176th Electrochemical Society Meeting, Hollywood, Fla, October 15-20, 1989.

41. X. Y. Qian, M. H. Kiang, J. Huang, D. Carl, N. W. Cheung, M. A. Lieberman, I. G. Brown, K. M. Yu and M. I. Current, Nucl. Instrum. Meth. Phys. Res. B55, 888 (1991).

42. X. Godechot, M. B. Salmeron, D. F. Ogletree, J. E. Galvin, R. A. MacGill, K. M. Yu and I. G. Brown, Mat. Res. Soc. Symp. Proc. 190, 95 (1991).

43. See, for instance, F. F. Chen in "Plasma Diagnostic Techniques", edited by R. H. Huddlestone and S. L. Leonard (Academic Press, N. Y., 1965).

44. J. F. Ziegler, J. P. Biersack and U. Littmark, in "The Stopping and Range of Ions in Solids", Vol 1, edited by J. F. Ziegler (Pergamon, N.Y., 1985). 
Table I.

Approximate parameter ranges for a large implanter facility. Actual values could be designed over a wide range.

\section{Size of Implanter}

- Ion beam extractor area

- Substrate surface area

- I/P power requirements

- Batch mode; possibly continuous mode $\sim$ up to several square meters

$\sim$ up to several square meters or more by mechanically scanning source or substrate

$\sim 100 \mathrm{~kW}$ for $100 \mathrm{keV}, 1$ Amp beam

(Pressure $<10^{-5}$ Torr)

\section{Beam and Implantation Parameters}

- Ion energy

- Beam current

- Extractor size

- Implantation size

- Beam power

- Species (eg) $\sim 20-390 \mathrm{keV}$

$\sim 100 \mathrm{~mA}-10$ Amperes

$0.5-2$ meters diameter; (or rectangular ok)

$\sim 1 \mathrm{~m}^{2} / \mathrm{sec}$ for dose $\sim 3 \times 10^{16} \mathrm{~cm}^{-2}$, for $\mathrm{I}_{\text {beam }} \sim 10 \mathrm{~A}$, limited by allowable substrate temperature rise

$\sim 1 \mathrm{~kW}-1 \mathrm{MW}$

$\mathrm{C}, \mathrm{Mg}, \mathrm{Al}, \mathrm{Sc}, \mathrm{Ti}, \mathrm{V}, \mathrm{Cr}, \mathrm{Mn}, \mathrm{Fe}, \mathrm{Co}, \mathrm{Ni}, \mathrm{Cu}$, $\mathrm{Zn}, \mathrm{Sr}, \mathrm{Y}, \mathrm{Zr}, \mathrm{Nb}, \mathrm{Mo}, \mathrm{Pd}, \mathrm{Ag}, \mathrm{Cd}, \mathrm{La}, \mathrm{Ce}, \mathrm{Pr}$, $\mathrm{Nd}, \mathrm{Sm}, \mathrm{Gd}, \mathrm{Dy}, \mathrm{Ho}, \mathrm{Er}, \mathrm{Tm}, \mathrm{Yb}, \mathrm{Hf}, \mathrm{Ta}, \mathrm{W}$, Ir, $\mathrm{Pt}, \mathrm{Au}, \mathrm{Th}, \mathrm{U}$.

\section{Cost}

- Capital cost $\sim \$ 1$ - 5 million

- Operating costs

$\begin{array}{ccccc}\text { Ibeam: } & 0.1 & 1 & 10 & \text { amperes } \\ \text { Cost: } & 1 & 0.1 & 0.01 & \begin{array}{c}\$ / \mathrm{cm}^{2} \\ \$ / \mathrm{m}^{2}\end{array} \\ & 100 & 10 & 1 & \begin{array}{c}1 \\ \end{array} \\ & & & & \text { for a dose } \sim 1 \times 10^{17} \mathrm{~cm}^{-2}\end{array}$




\section{Eigure Cantions}

Fig. 1 Mevva V ion source. (CBB892-1120).

Fig. 2 Schematic of the laboratory ion implanter based on the Mevva $V$ ion source. (XBL896-7641B).

Fig. 3 DC plasma gun within a magnetic guide field with current collector plate at the end. (CBB901-300).

Fig. $450-\mathrm{cm}$ diameter beam formation electrodes, disassembled, together with a smaller embodiment of Mevva ion source and two sub-miniature versions. (CBB926-5122).

Fig. 5 Rutherford Backscattering spectra (RBS) for $\mathrm{Y}$ into Si. The dashed curve is from the sample without pulsc biasing and the solid curve from that with pulse biasing. The depth of implantation is approximately $500 \AA$ and the dose is $1 \times 10^{16} \mathrm{~cm}^{-2}$. (XBL9010-3416).

Fig. 6 RBS spectrum for Pt into/onto Al with interface mixing. (XBL914-871).

Fig. 7 Rutherford Rackscattering spectra for a Ti-Y multilayer structure on Si with ion beam mixing at the first $\mathrm{Si}-\mathrm{Y}$ and the final Ti-Y interfaces. (XBL9010-3417).

3. 8 "3-D" Auger depth profiles of $\mathrm{Al}_{2} \mathrm{O}_{3}$ film on stainless steel with atomic mixing at the interface, showing $\sim 1000 \AA$ thick intermixed zone. (XBL928-1833). 


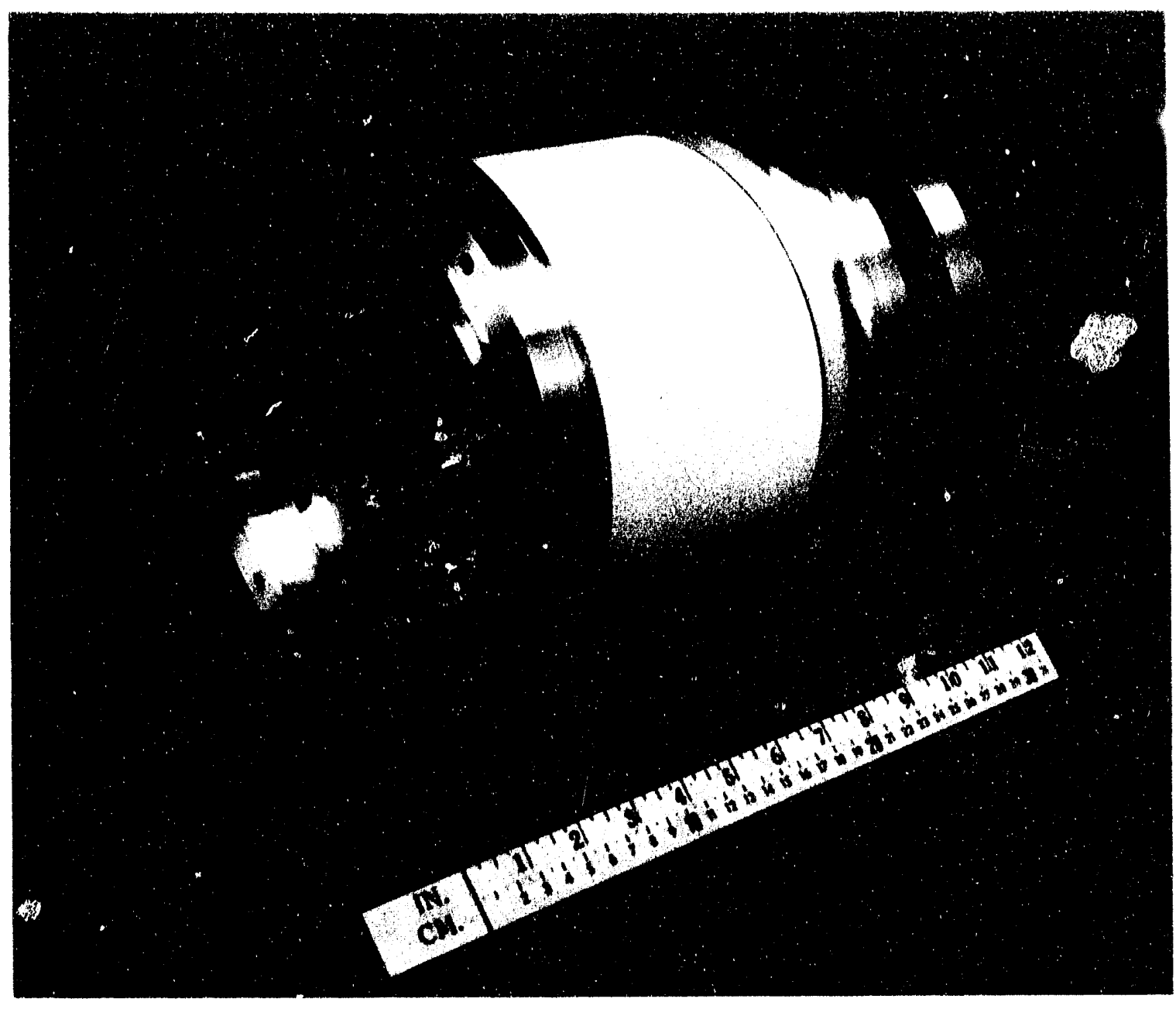

CBB 892-1120

Figure 1 


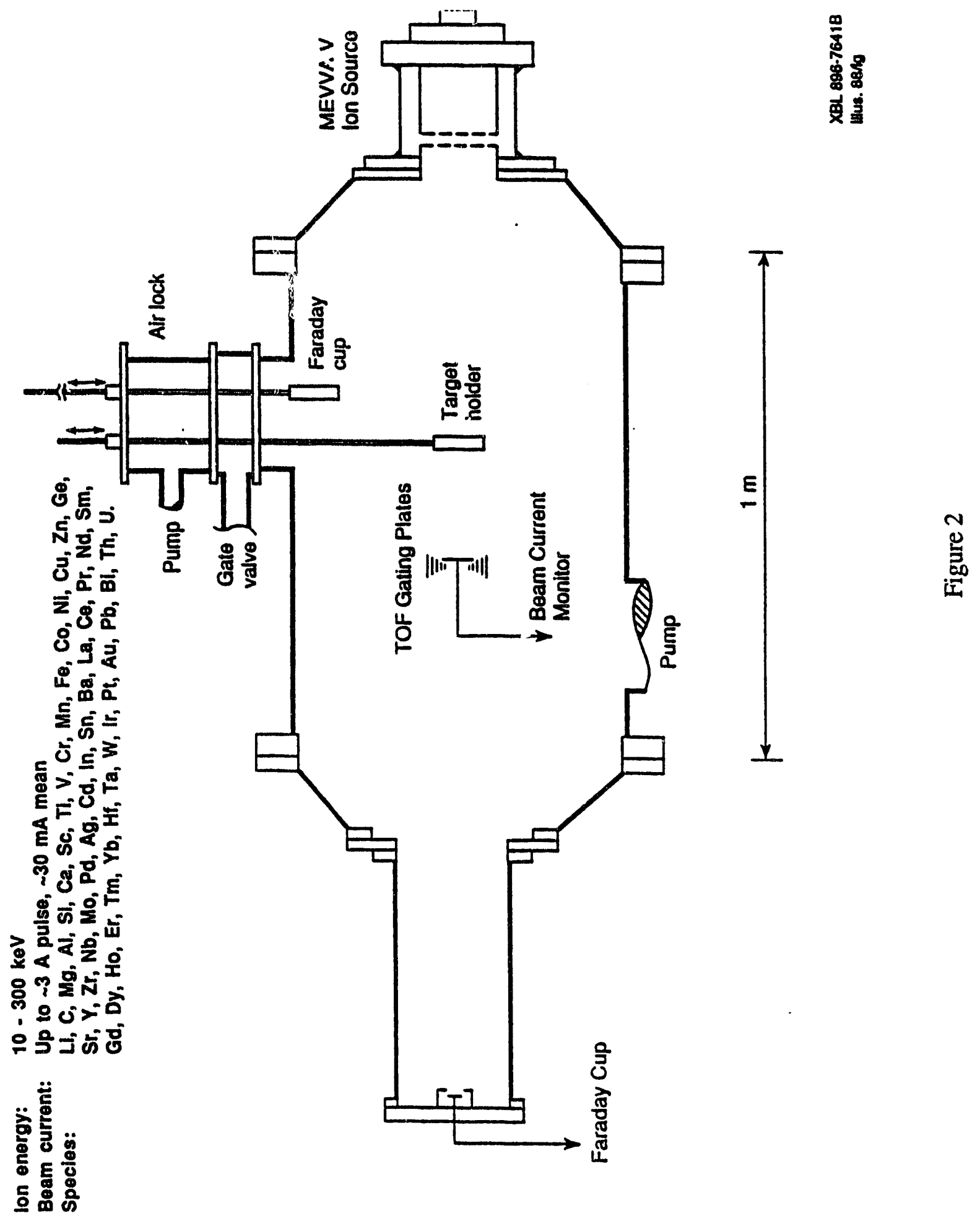




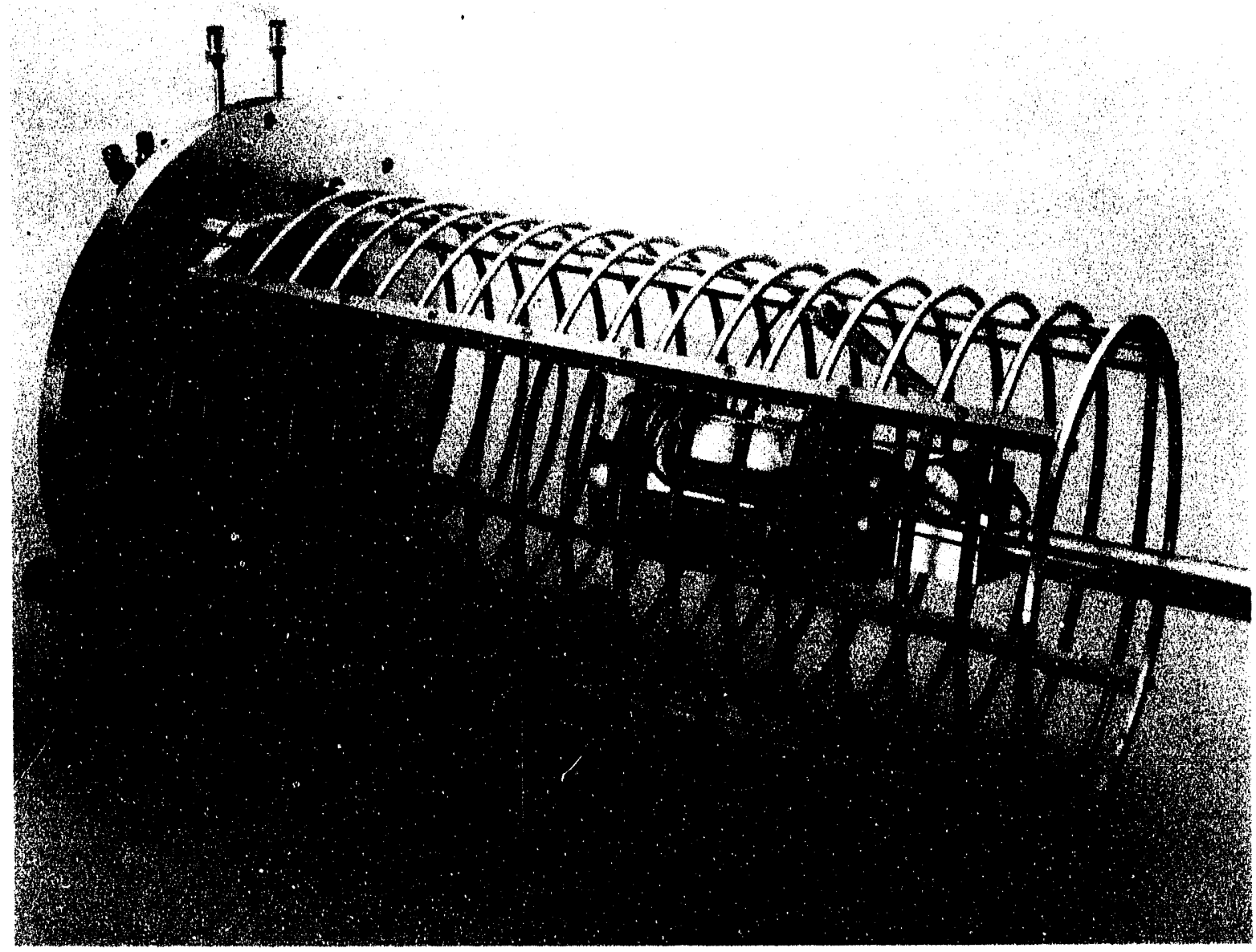

CBB 901-300

Figure 3 


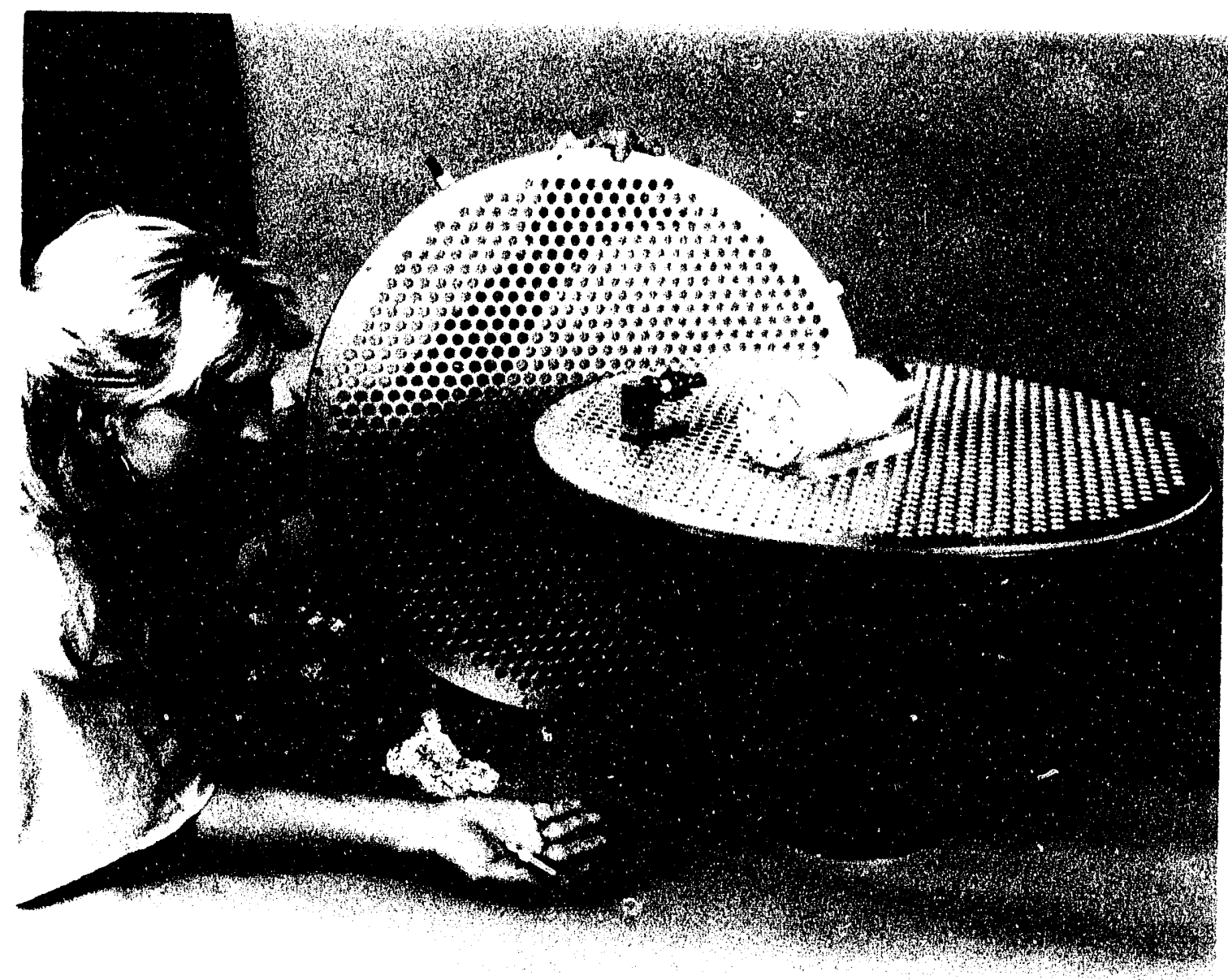

CBB 926-5122

Figure 4 


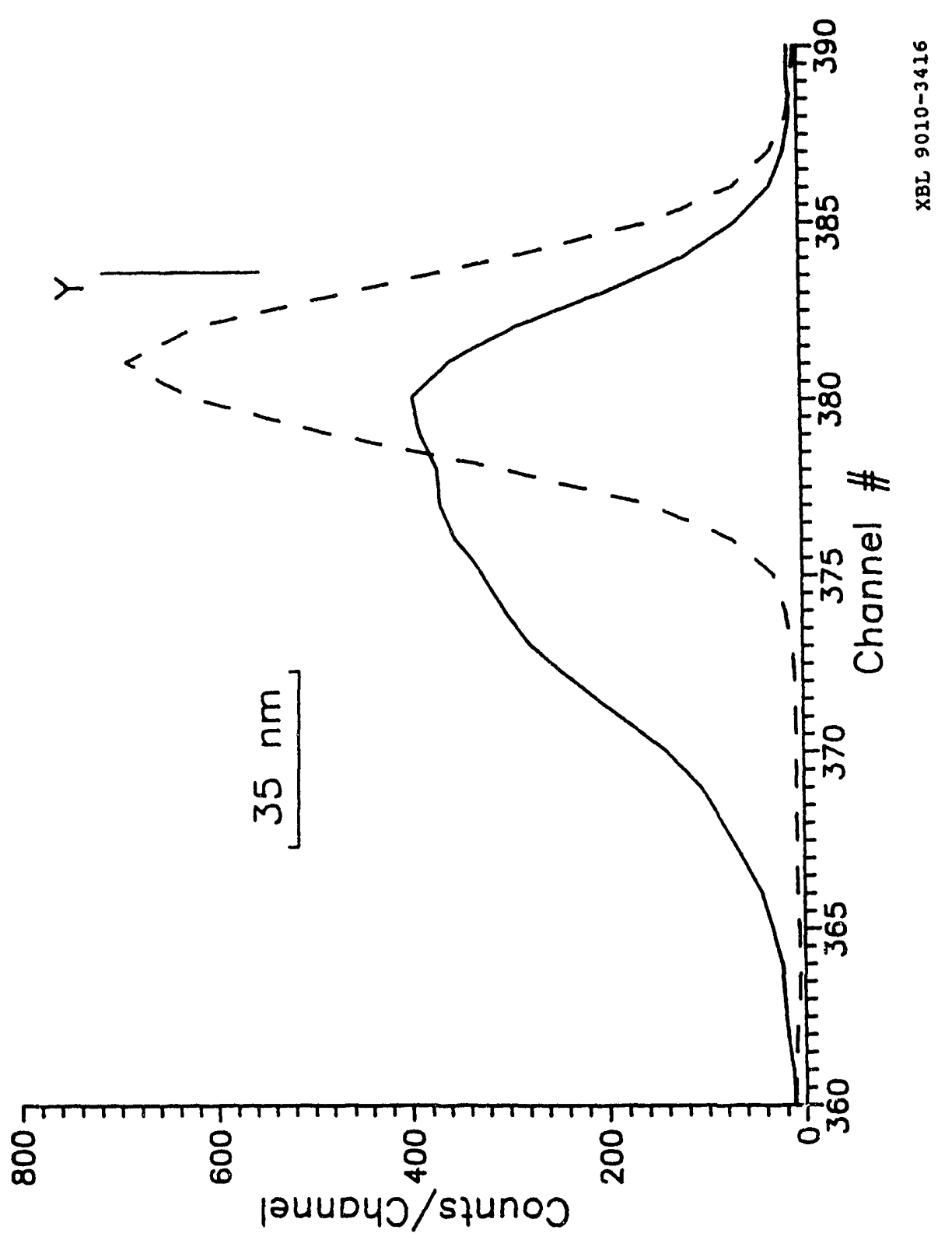

翯 


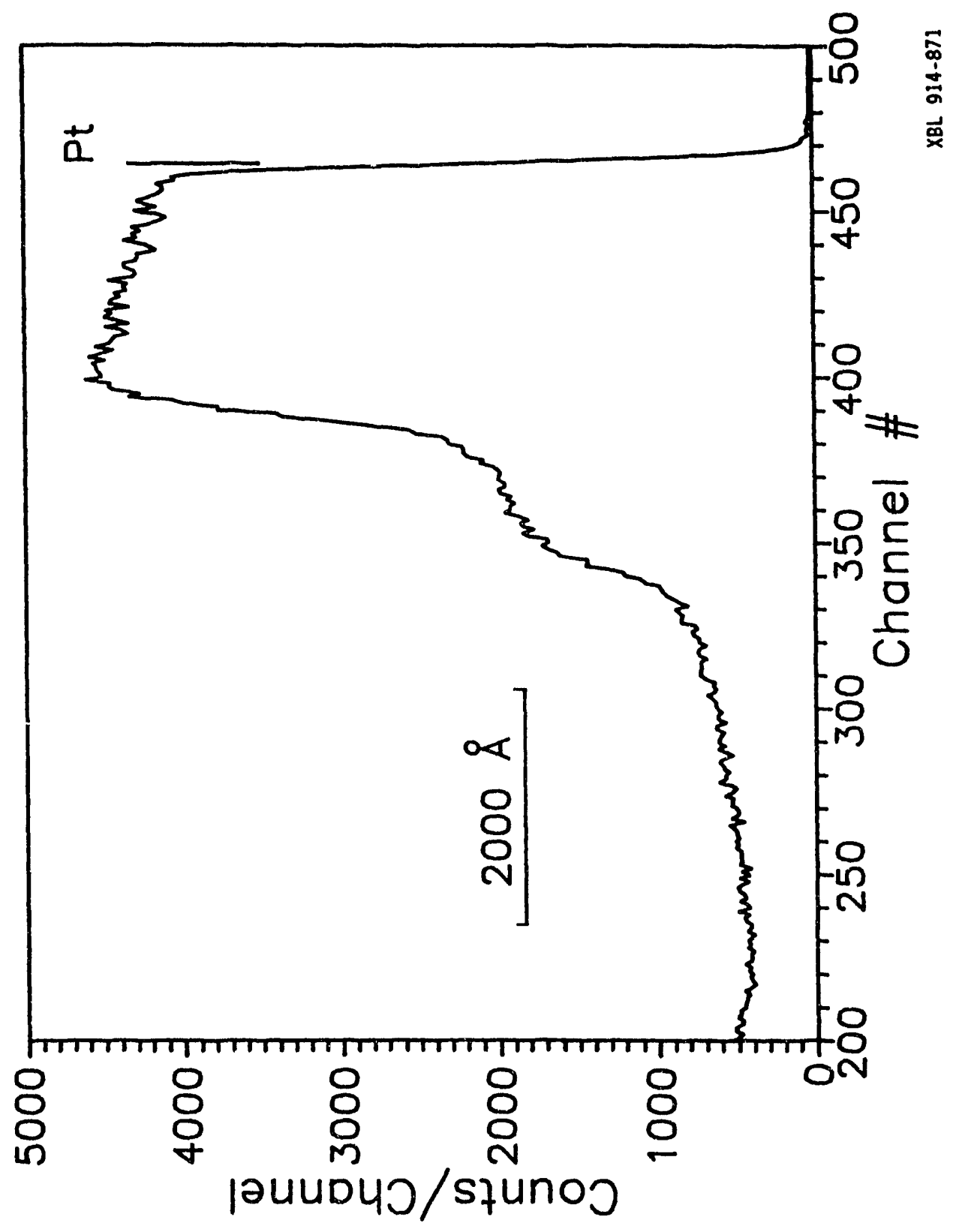




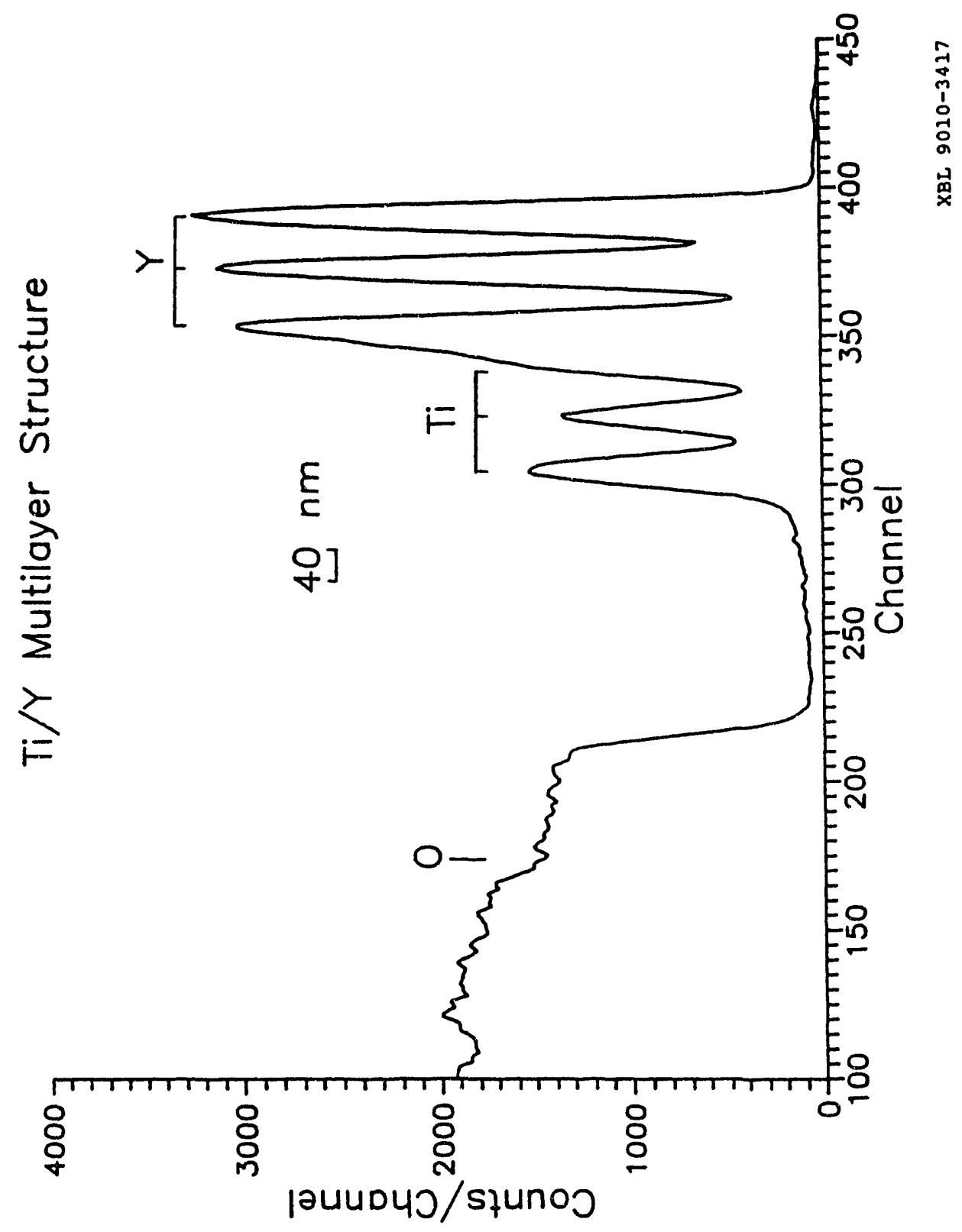



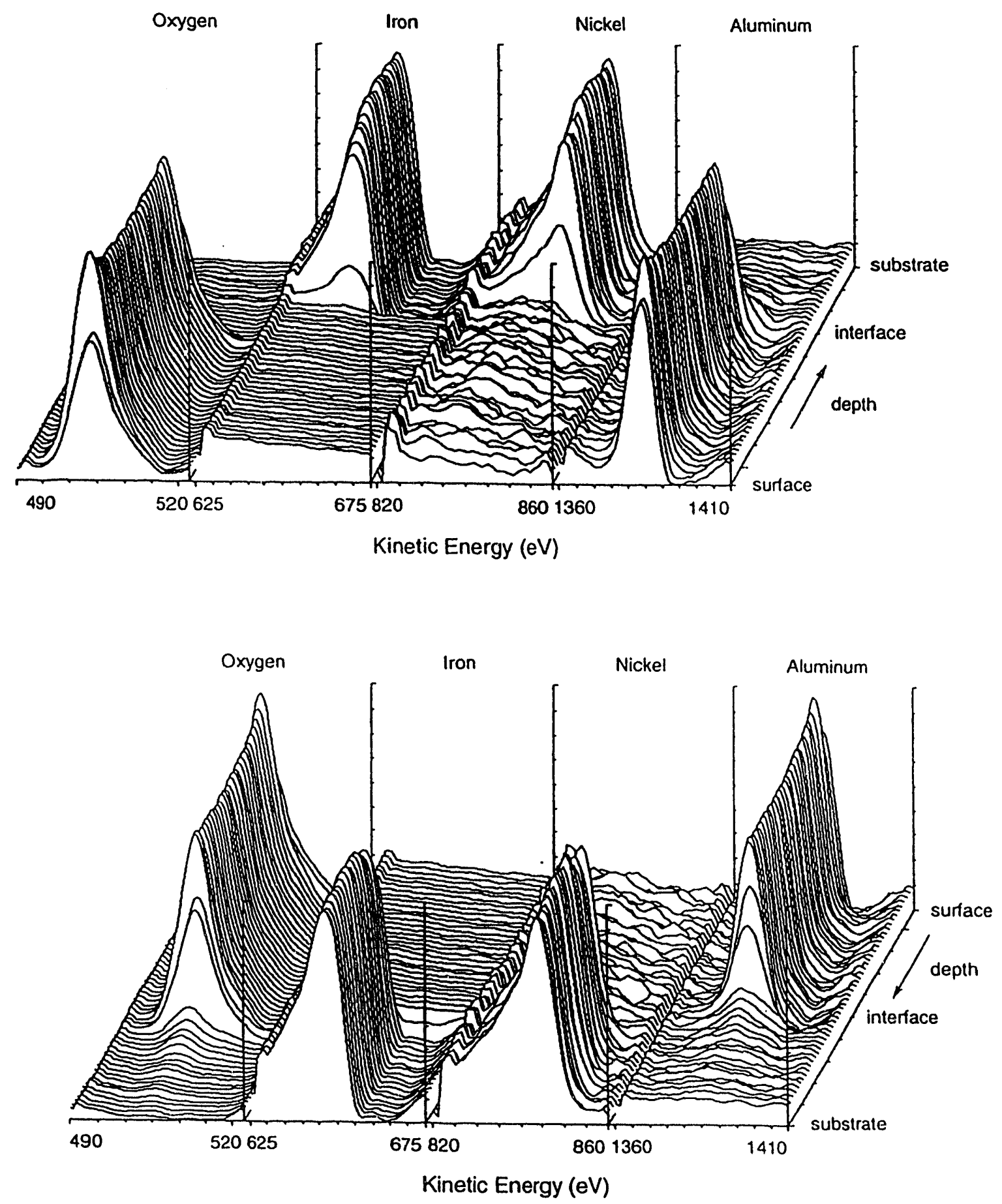

XBL 928-1833 

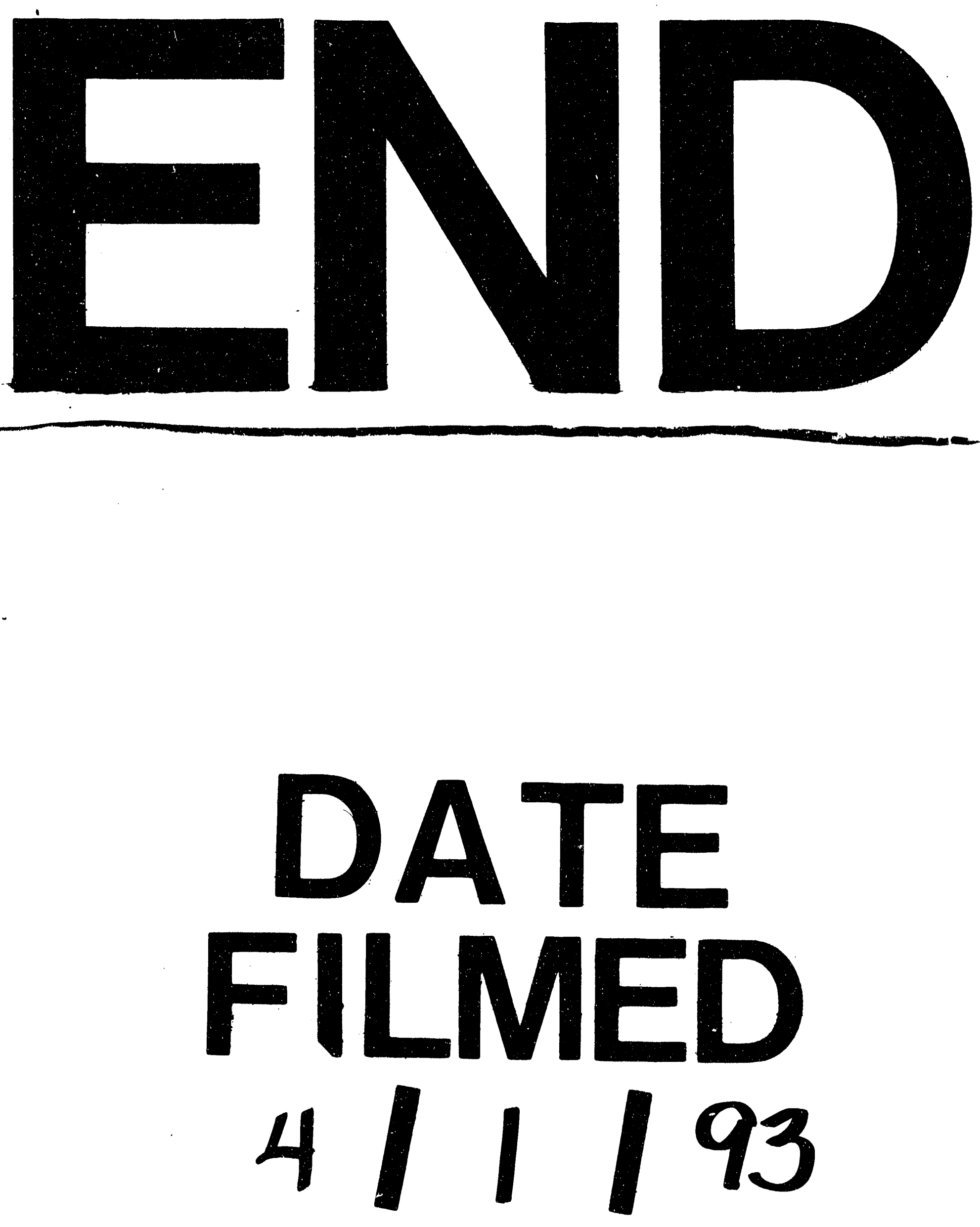
